\title{
Is enhancing recovery after pancreatic cancer surgery even possible? - a narrative review
}

\author{
Monish Karunakaran ${ }^{1,2}$, Savio George Barreto ${ }^{3,4}$ \\ ${ }^{1}$ Department of Gastrointestinal Surgery, Gastrointestinal Oncology, and Bariatric Surgery, Medanta Institute of Digestive and Hepatobiliary \\ Sciences, Medanta, The Medicity, Gurgaon, India; ${ }^{2}$ Department of Liver Transplantation and Regenerative Medicine, Medanta, The Medicity, \\ Gurgaon, India; ${ }^{3}$ College of Medicine and Public Health, Flinders University, South Australia, Australia; ${ }^{4}$ Division of Surgery and Perioperative \\ Medicine, Flinders Medical Center, Bedford Park, Adelaide, South Australia, Australia \\ Contributions: (I) Conception and design: Both authors; (II) Administrative support: None; (III) Provision of study materials or patients: None; (IV) \\ Collection and assembly of data: None; (V) Data analysis and interpretation: None; (VI) Manuscript writing: Both authors; (VII) Final approval of \\ manuscript: Both authors. \\ Correspondence to: Savio George Barreto. Department of Surgery, Flinders Medical Centre, Bedford Park, South Australia, 5042, Australia. \\ Email: georgebarreto@yahoo.com; savio.barreto@sa.gov.au.
}

\begin{abstract}
Objective: This narrative review traces the evolutionary journey of ERAS ${ }^{\circledR}$ with emphasis on challenges specific to pancreatic cancer. This article will also attempt to explore the barriers to routine ERAS $^{\circledR}$ implementation and offers possible solutions to increasing its uptake and compliance rates.

Background: Enhanced Recovery After Surgery $\left(\right.$ ERAS $^{\circledR}$ ) represents a paradigm shift in the perioperative management of surgical patients using a multi-modality approach each of which is based on best available evidence. ERAS $^{\circledR}$ has come a long way since its inception and can now be regarded as one of the promising ways forward in the perioperative management of patients undergoing pancreatic surgery.

Methods: We identified 37 studies on the impact of ERAS ${ }^{\circledR}$ in pancreatic surgery, published over the last 2 decades. Implementation of ERAS ${ }^{\circledR}$ helped in shortening the length of stay without an increase in hospital re-admissions, morbidity, or mortality. Compliance to ERAS $^{\circledR}$ is relatively low following pancreatic surgery, with a reported median compliance of $52 \%$. Elderly patients or those with higher BMI, higher ASA scores, hypoalbuminemia, cardiac comorbidities or longer operative duration are more prone for deviations.

Conclusions: ERAS pathways have been successful in achieving their intended outcomes, despite low compliance. Complementing existing ERAS $^{\circledR}$ pathways with prehabilitation measures, risk-stratified clinical pathways and the accessibility to step-down care facilities following discharge may facilitate its wider utilisation.
\end{abstract}

Keywords: Outcomes; enhanced recovery; pancreatic surgery; quality; compliance

Submitted Mar 20, 2021. Accepted for publication May 08, 2021.

doi: $10.21037 /$ cco-21-36

View this article at: http://dx.doi.org/10.21037/cco-21-36

\section{ERAS $^{\oplus}$ : the road travelled so far!}

Introduced by Kehlet et al. in 1997 (1), Enhanced Recovery After Surgery $\left(\mathrm{ERAS}^{\circledR}\right)$ is a holistic, multi-pronged, interdisciplinary framework which utilizes evidence-based practices to decrease surgical stress, maintain physiologic homeostasis, and facilitate recovery of patients (2). Pioneering work by Kehlet et al. (3) showed that patients undergoing open sigmoid resection could be discharged in 2 days, at a time when the average length of stay was around 10 days in most of the centres. The concept survived initial scepticism, and its acceptance increased as it became evident that outcomes improved with standardized implementation of ERAS $^{\circledR}$ protocols (4). Encouraged by the dramatic reduction in hospital stay, without compromising patient outcomes, and an increase in functional recovery following 
structured synchronous implementation of an ERAS $^{\circledR}$ program in elective colonic surgery in Netherlands, led to the founding of the ERAS ${ }^{\circledast}$ Society in 2010 (5). This society is an international non-profit academic society aiming wider dissemination and periodic appraisal of the ERAS $^{\circledR}$ guidelines.

Although the initial experience with ERAS $^{\circledR}$ was largely based on reports of its use and success in colorectal surgery, other surgical subspecialties began to adapt these principles with the overarching aim of enhancing patient recovery. It is important to note that the benefits of ERAS ${ }^{\circledR}$, compared to conventional care, in terms length of hospitalization and reduced overall complications continued to be appreciated in colorectal cancer surgery despite the uniform adoption of laparoscopic surgery (6). Recent meta-analyses in oesophageal and gastric cancer have also demonstrated the benefits of adoption of the principles of ERAS ${ }^{\circledR}$ on the length of hospital stay and time to functional recovery without negatively influencing overall morbidity rates $(7,8)$. In Urology, Orejón et al. (9) noted a reduced utilization of Intensive Care Unit stay as well as the need for transfusion of blood products following radical cystectomy for bladder cancer. Similarly, the benefits of ERAS ${ }^{\circledR}$ on patient satisfaction, along with reduced length of hospital stay and overall costs have been documented following its adoption for gynaecological malignancies (10). The use of ERAS ${ }^{\circledR}$ has been successfully trialed in thoracic surgery with increasing compliance found to correlate with improved outcomes in lung resections for cancer (11) while it even enabled sameday discharge following mastectomy for breast cancer (12). We present the following article in accordance with the Narrative Review reporting checklist (available at http:// dx.doi.org/ 10.21037/cco-21-36).

\section{Rationale and perceived benefits of ERAS ${ }^{\circledR}$}

The scope of ERAS ${ }^{\circledR}$ extends beyond its commonly perceived aim of shortening hospital stay (13). It emphasizes the creation of a supportive environment for the patient to have an optimal perioperative experience that, in turn, reduces surgical stress (14). ERAS ${ }^{\circledR}$ guidelines encompass precisely defined elements for all stages of perioperative care (15), with the derived benefits attributed to either a significant improvement in one or two influential individual elements, summation of marginal gains achieved by adherence to the entire pathway, or a combination of both (16).

Surgical stress is borne out of a combination of catabolicneuroendocrine and inflammatory-immunological responses, culminating in a state of insulin resistance (17). This causes accelerated protein breakdown and increased production of endogenous hepatic glucose (18), which is partly utilized by the cells for glycolysis with the rest directed towards the generation of oxygen radicals with resultant inflammation (19). Practices like carbohydrate loading (20) and early initiation of oral/enteral feeds (21) are based on this understanding, which may mitigate insulin resistance $(22,23)$. Early enteral feeds also maintain the gut-mucosal barrier, which may help in the reduction of infectious complications (24). Pain contributes to the insulin resistance by sympathetic stimulation and systemic release of pro-inflammatory cytokines (25). Pain relief with neuraxial blockade decreases insulin resistance by attenuation of hormonal response (cortisol and epinephrine), an effect which is not shown by opioids or non-steroidal anti-inflammatory drugs (NSAIDs) (26). Similarly, normothermia diminishes the perioperative release of catecholamines and decreases loss of body nitrogen (27). Though the underlying mechanisms are yet to be elucidated, early mobilization ameliorates fatigue and facilitates functional recovery (28), in addition to reducing thrombo-embolic complications. Post-operative ileus is multifactorial in origin and the causative factors include neural sympathetic inhibitory reflexes, opioids, intestinal inflammatory responses and perioperative fluid excess (29-31). Care bundles consisting of chewing gum (32), epidural analgesia (33), restrictive fluid supplementation (34), avoidance of nasogastric tubes (35), early initiation of oral diet and mobilization (36) and pharmacological measures like peripheral opioid antagonists (37) have contributed to expedite the recovery from postoperative ileus. These observations are of increasing relevance to pancreatic surgery because, contrary to the experience from colorectal surgery, available evidence in pancreatic surgery does not endorse the role of minimal access surgery in reducing the stress response (38).

Though ERAS ${ }^{\circledR}$ pathways appear to have improved surgical outcomes (39), further research is warranted to help decipher the mechanisms underlying the inflammatory and neuro-humoral surgical stress responses (40), the optimal choice of perioperative fluid management (which is neither liberal nor too restrictive) $(41,42)$, mechanisms and prevention of orthostatic intolerance (43), postoperative cognitive dysfunction including sleep promotion (44), a reduction in the neuro-inflammatory response (45) and measures to improve compliance to pathways (46). It is also important to realize that the ultimate success of an ERAS $^{\circledast}$ 
program depends on clinical initiative and leadership, inter-departmental coordination, and continuous audit of the compliance and outcomes (47) to inform strategies for improving the process.

\section{ERAS $^{\circledR}$ in pancreatic surgery}

Pancreatic cancer is a deadly disease, which currently ranks fourth in cancer-related mortality and is expected to ascend to second position in the Western world by 2030 (48). Given the complex nature of the technicality of pancreatic surgery, it is commendable that overall perioperative mortality has been reduced to $<3 \%$, at some high-volume centres (49). However, high post-operative morbidity continues to challenge pancreatic surgeons (50). This area of pancreatic surgery certainly lends itself to further improvement (51). Clinical pathways, inspired by the ERAS $^{\circledR}$ guidelines $(52,53)$, have been implemented to standardize care and contain costs.

It has been postulated that the inherently complex nature of pancreatic surgery, with its attendant higher rates of post-operative morbidity, being performed on a relatively weak patient likely contributed to the reluctance among pancreatic surgeons to adopt ERAS ${ }^{\circledR}$ pathways as overwhelmingly as was noted with other surgeons (52). The typical pancreatic cancer patient is generally malnourished due to a combination of poor intake, pancreatic exocrine insufficiency and malignant cachexia (54). Tumours in the head of pancreas usually present with obstructive jaundice, which in turn predisposed to cholangitis, sepsis, coagulopathy and renal failure. Sepsis is further compounded by secondary gut failure with increased bacterial translocation via the portal system or significant biliary colonization $(55,56)$. Vitamin $\mathrm{K}$ malabsorption leads to hypoprothrombinemia and a prolonged PT (57). Furthermore, new-onset diabetes mellitus, believed to be due to increased tumoral production of amylin and destruction of $\beta$-islets, occurs in about $70 \%$ of patients (54). All of these factors serve to challenge the recovery of pancreatic cancer patients who are amenable to surgery. In light of these challenges, there appears a need to need to review the level of integration of ERAS protocols into the perioperative care of pancreatic cancer patients, identify potential barriers to its widespread implementation and search for possible solutions to overcome these hurdles.

The authors performed a literature search of the major reference databases (PubMed, Embase, Scopus and Google Scholar) in accordance with PRISMA
(Preferred Reporting Items for Systematic Reviews and Meta-Analyses) (58) guidelines, to identify studies published between January 2000 to January 2021 that reported on the impact of Clinical/ERAS ${ }^{\circledR}$ pathways on outcomes following pancreatoduodenectomy (PD). Articles were searched using MeSH (Medical Education Subject Headings) keywords: "Enhanced recovery OR Clinical pathways", Pancreaticoduodenectomy OR Pancreatoduodenectomy, "Pancreatic cancer OR Pancreatic carcinoma OR Pancreatic adenocarcinoma". Studies with a clearly defined clinical pathway for peri-operative care were included, while those without a description of clinical care pathways elements and non-English language studies were excluded. Study selection process and PRISMA flow diagram for identifying studies are shown in Figure 1. The search strategy identified 37 studies (https://cdn. amegroups.cn/static/public/cco-21-36-1.pdf) (59-83) published (84-96) in the last 2 decades, including 4 RCTs $(81,83,87,88)$. On comparing the components (pre-, intraand post-operative) of the pathways in these studies, we found considerable heterogeneity amongst institutional protocols. This may be attributed to the practice of "glocalization", which refers to simultaneous occurrence of both universalizing and particularizing tendencies in a contemporary system (97). Again, we noted a low representation of pre- $(59,61,62,67,72,73,76,78,80,81,94,95)$ and intra-operative $(59-62,64,67,70,72,73,76,78,80,94,95)$ components in many of the institutional pathways. It is quite possible that some routine practices would not have been itemized as pathway components. However, we believe that operationalizing care by means of pathway components can bring in standardization as well as improve adherence. Similar to the results observed in other surgical populations (98), majority of the studies reported that primary length of stay was significantly shorter $(59,61$ $64,66,67,69,70,73,75-78,80,81,83,87)$ in the enhanced recovery arm without an increase in complication rates $(59-63,65,67,69,70,73,74,76,77,80,81,83,87)$, hospital readmissions $(59-65,67,73,74,76,79,83,87)$ or mortality (59-62,65-67,69,70,74,76,79,81). At the same time, we would like to make the reader cognizant to the fact that most of these studies have compared the outcomes of ERAS $^{\circledR}$ pathway with traditional, often historical, care pathways which often does not account for the secular trends and fails to capture the entire magnitude of benefit.

Though ERAS ${ }^{\circledast}$ implementation can be believed to have brought about quality improvement, one should not forget that compliance (overall median compliance of $52 \%$ 

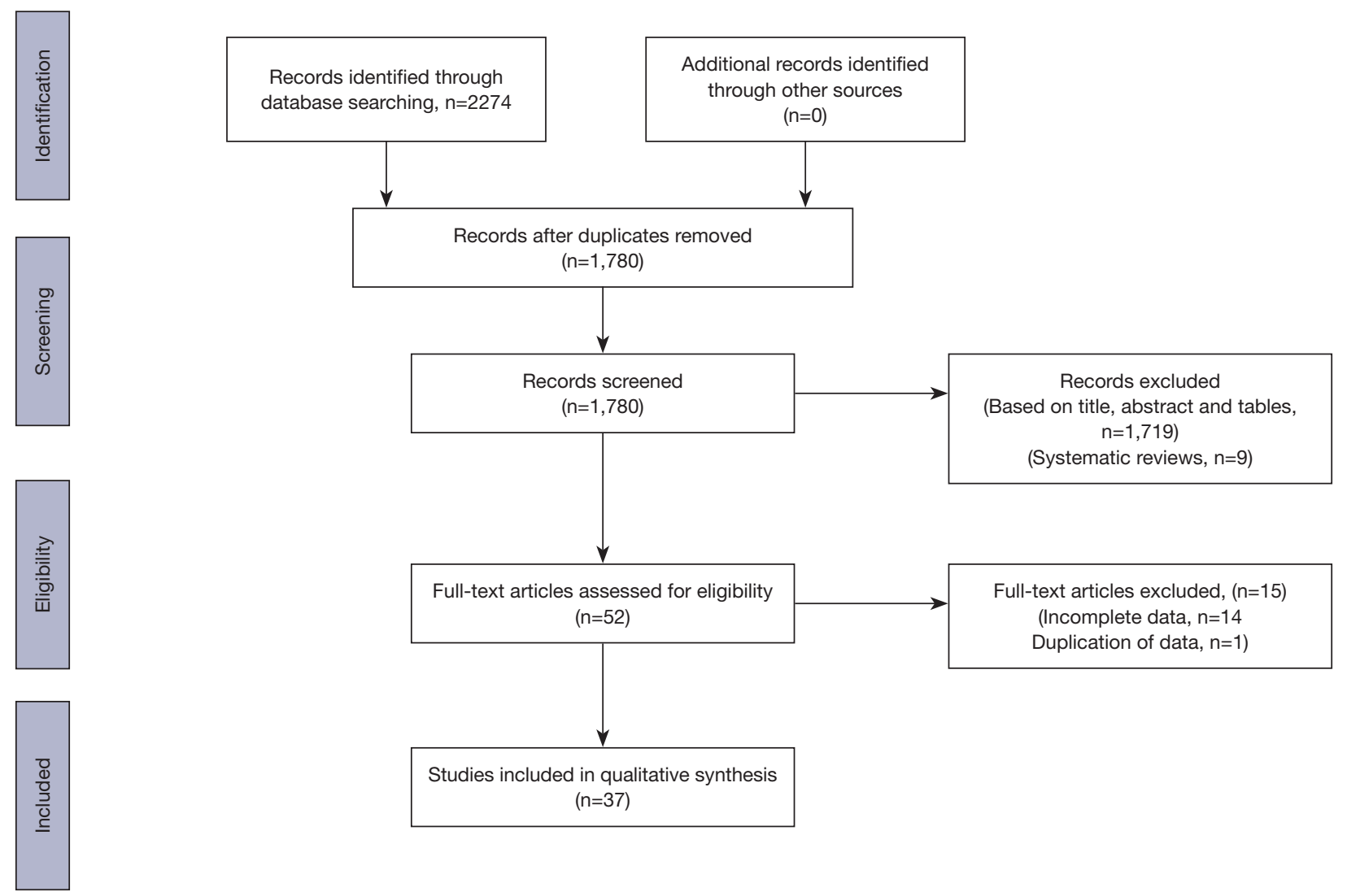

Figure 1 PRISMA diagram for study selection.

Table 1 Compliance to ERAS ${ }^{\circledast} /$ clinical pathway components following pancreatic surgery

\begin{tabular}{lcccc}
\hline Study & Study design & $\mathrm{n}$ & $\begin{array}{c}\text { Number of clinical pathway } \\
\text { components (post-op) }\end{array}$ & Overall compliance (\%) \\
\hline Williamsson et al. 2019 (Sweden) (99) & Retrospective & 160 & 8 & 52 \\
Roulin et al. 2020 (Multicentre) (91) & Prospective & 390 & 9 & 30 \\
Capretti et al. 2020 (Italy) (93) & Prospective & 205 & 6 & 68.4 \\
Karunakaran et al. 2020 (India) (100) & Retrospective & 162 & Not mentioned & 53 \\
St-Amour et al. 2020 (Switzerland) (101) & Retrospective & 89 & 36 \\
\hline
\end{tabular}

across studies) to these pathways in pancreatic surgery has not been as robust as with other surgical subspecialties $(91,93,96,99,100)$ (Table 1$)$. The lack of compliance is mainly seen with the postoperative component of the pathways, which not only display maximal variance, but have also been noted to best correlate with the final outcomes (91). Braga et al. (65) highlighted that patients with early postoperative low compliance to the ERAS $^{\circledR}$ pathway had a higher incidence of complications. Karunakaran et al. (100) showed that less than $10 \%$ of patients following PD display a $100 \%$ compliance and deviation from $>50 \%$ of clinical pathway components is associated with an increased risk of 90-day (but not 30-day) readmission, which signals the importance of continued close surveillance in these patients (102).

Most studies have used length of hospital stay (LoS) to evaluate the performance of their care pathways. Taking a closer look at the relationship between adherence to individual pathway components and LoS, failure to remove 
Table 2 Factors predicting deviations from ERAS $^{\circledR} /$ clinical pathways

\begin{tabular}{lll}
\hline \multirow{2}{*}{ Study (author and year, reference) } & Factors & Intra-operative \\
\cline { 2 - 3 } & Pre-operative & Longer operative duration \\
Tankel et al., 2020 (Israel) (92) & Male gender & Longer operative duration; pancreatic \\
Capretti et al., 2020 (Italy) (93) & Age; higher BMI & texture \\
Karunakaran et al., 2020 (India) (100) & Higher BMl; hypoalbuminemia; cardiac co-morbidities & Longer operative duration \\
Zhang et al., 2020 (China) (103) & Age $>70$ years; hypoalbuminemia; high ASA score & \\
\hline
\end{tabular}

ASA, American Society of Anesthesiologists; BMI, body mass index.

the naso-gastric tube (NGT) on POD2 (103), intolerance to liquid diet on post-operative day (POD) 3 (103), inability to tolerate solid food by POD $5(94,100)$, re-insertion NGT (100), need to continue antibiotics beyond POD 2 (100) and inability to remove drain on the designated day (94) were predictors of longer hospitalization. This leads one to infer that post-operative pancreatic fistula (POPF), delayed gastric emptying (DGE), and infectious complications are major causes of deviations. These, in turn, lead to a prolonged LoS. The utility of Clinical pathways in this patient cohort is to serve the early identification of complications thereby reducing 'failure to rescue' rates (104).

\section{Barriers to $\mathrm{EAS}^{\circledR}$ implementation and possible solutions}

Compliance may be deconstructed into two components: provider (Surgeon-related) compliance and recipient (patient-related) compliance. Despite its proven benefits, the universal acceptance of ERAS ${ }^{\circledR}$ has also been impacted by the fact that it challenges many deeply-entrenched surgical dogmas (105). It is important to address these concerns that drive a resistance to change because the benefits of ERAS ${ }^{\circledR}$, e.g., decrease in complications and reduced LoS depends on the degree of compliance (106). Pędziwiatr et al. (107) highlighted that a multidisciplinary team needs at least 40 cases and 6 months to reach satisfactory level of adherence to the protocol. For initiation of a program, ERAS ${ }^{\circledR}$ society recommends the incorporation of ERAS ${ }^{\circledR}$ Implementation Process (EIP), a systematic training program which consists of four specific workshops over 8-10 months (108), in the training of the team involved in delivering strategies aimed at enhancing recovery. Based on the "breakthrough method" (109), measurable goals are defined, actions and plans are put into practice, outcomes assessed, followed by appropriate adjustments [Plan-Do-Study-Act (PDSA)]. This process is repeated multiple times over the implementation and maintenance phases. ERAS Interactive Audit System (EIAS), an online interactive software, can be used to assess compliance with the guidelines, length of stay, readmissions, and complications (108). Measures to increase clinician involvement, identification of local evidence-practice gaps, adaptation of evidence to the local circumstances, periodic staff education sessions, incorporation of reminder systems, and audit and feedback are paramount to ensure optimal compliance (110). However, one must also be aware of the findings of Roulin et al. (111) who noted that reasons for non-compliance in the long-term are usually medically justified and were mostly observed in the postoperative period.

When developing ERAS $^{\circledR} /$ clinical pathways, it is important for the team to understand, and develop strategies to address, patient-related factors that have been shown to impact on compliance. It has become increasingly clear that the patients who are able to adhere to the ERAS ${ }^{\circledR}$ pathways have significantly better outcomes that those do not. The corollary is even more important, namely, being able to identify the subset of patients who are likely to deviate from the pathways $(92,93,100,103)$ (Table 2). This knowledge can possibly usher in optimization measures with the overarching aim of improving outcomes. POPF is one of the major determinants of post pancreatectomy morbidity and mortality (112). Main pancreatic duct diameter $<3 \mathrm{~mm}$ (113) and soft texture of the pancreatic remnant are important risk factors for the development of POPF (114). Higher body mass index (BMI) is a known predisposing factor for increased intra-operative bleeding (115) and longer operative duration (116) during PD, surgical site infections $(117,118)$ and longer hospitalization $(119,120)$ following PD. Inclusion of BMI in 3 scoring systems (121-123) predicting POPF 
testifies its importance. Furthermore, certain racial groups, especially Asians are known to incur greater metabolic injury even at lower BMI (124). This, along with other adverse factors like hypoalbuminemia $(100,125,126)$ and pre-existing comorbidities especially cardiac (100), prepare a conducive milieu for the complications to develop.

The overriding question is can these hurdles be overcome? If so, what interventions can be instituted? Prehabilitation programs promise, at least in principle, to increase the overall fitness of a pancreatic cancer patient and thus improve their surgical candidacy by improving their ability to withstand the postoperative stress response (127). Studies examining the role prehabilitation in pancreatic cancer have been detailed in Table 3. Three studies specifically looked at the impact of prehabilitation on post-operative outcomes following pancreatic cancer surgery $(130,131,133)$. While all of them reported a significant decrease in the LoS in the prehabilitation arm [Ausania et al. (133) 11.4 vs. 13.2 days, $\mathrm{P}=0.049$; Nakajima et al. (131) 23 vs. 30 days, $\mathrm{P}=0.045$; Kitahata et al. (130) 16 vs. 24 days, $\mathrm{P}=0.001$ ], there were no differences in major or minor complications, except for a significant decrease in DGE (1\% vs. 9\%, $\mathrm{P}=0.01)$ (133) and postoperative pulmonary complications $(0.9 \%$ vs. $4.3 \%$, $\mathrm{P}=0.011)$ (130) in the prehabilitation group. Bundred et al. (139) advocate on developing tele-prehabilitation programs consisting of home-based standardized exercise, nutritional and psychological interventions with remote monitoring and emphasize on nutritional interventions in patients with sarcopenia or sarcopenic obesity. With the available data, it appears safe to assume that prehabilitation interventions in pancreatic cancer surgery are feasible and safe (139). However, current literature suffers from some common deficiencies including small sample sizes with no standardized pre-intervention frailty assessment, focus on sarcopenia, a component of cachexia, rather than cachexia itself (140), heterogeneity in protocols with varying combinations of nutritional and exercise interventions and the end points are often surrogate markers of frailty improvement, rather than their effect on resectability rates, post-operative outcomes or disease free survival or overall survival. Out of the general concerns in universally recommending prehabilitation prior to pancreatic cancer surgery, the most important ones are the lack of direct association between prehabilitation and improved perioperative outcomes (141) and the inherent risk of such an approach potentially delaying surgery in a cancer that is fraught with a risk of rather rapid progression.
Prehabilitation tends to be shorter in patients undergoing upfront surgery $(130,131,133)$, while it ranged from 2 to 6 months with neoadjuvant therapy $(129,132)$. The adoption of neoadjuvant treatment protocols even for patients with resectable cancers may offer an opportunity to trial the safe implementation of prehabilitation.

\section{Future directions}

The acceptance of ERAS ${ }^{\circledR}$ in pancreatic surgery has been slow. However, there has been a growing movement towards adopting specific components (post-surgical clinical pathways) of $\mathrm{ERAS}^{\circledast}$ tailored to the problems inherent to pancreatic cancer surgery. The importance of a higher level of engagement, to bridge the gap between our knowledge of surgical pathophysiology, surgeon attitudes and actual peri-operative practices is warranted if we are to truly incorporate ERAS $^{\circledR}$ into pancreatic surgery. We need to clarify the minimum acceptable level of compliance following PD to improve outcomes and focus on measures to increase compliance (107). We need to incorporate patient-reported outcome measures (PROM) (142) to understand some of the barriers and increase patient participation and to enhance their experience. ERAS ${ }^{\circledast}$ pathways have shifted a significant portion of patient convalescence from the hospital to an external outpatient setting, which makes it pertinent to examine different barriers to post-discharge functional recovery and the choice of (pre- and postoperative) rehabilitation, preferably customized to the procedure and the patient. We suggest a 3-pronged approach in the efforts towards improving the compliance rates to ERAS $^{\circledR}$ or clinical pathways: Patient Prehabilitation, Periodic Provider (Treating team) education and training, and Progressive Refinement of the Clinical Pathways. Refinement measues may include devising Personlized or Risk-Stratified Clinical Pathways $(74,143)$, with the "risk" being estimated based on factors such as peroperative BMI, co-morbidities or likelihood of post-operative pancreatic fistula, as well as addition of complimentary elements to the pathways like "Perioperative Surgical Home" (PSH) (144) and/or tele-discharge program (145) with "virtual" visits in the post-operative period would make ERAS $^{\circledast}$ safer, leading to increased acceptance and sustained improvements in patient care. From a clinician's or policymaker's perspective, we certainly need to dissect out the economic implications of ERAS protocols, as concrete proof of financial gains in terms of grossly positive projected return on investment (108), in 


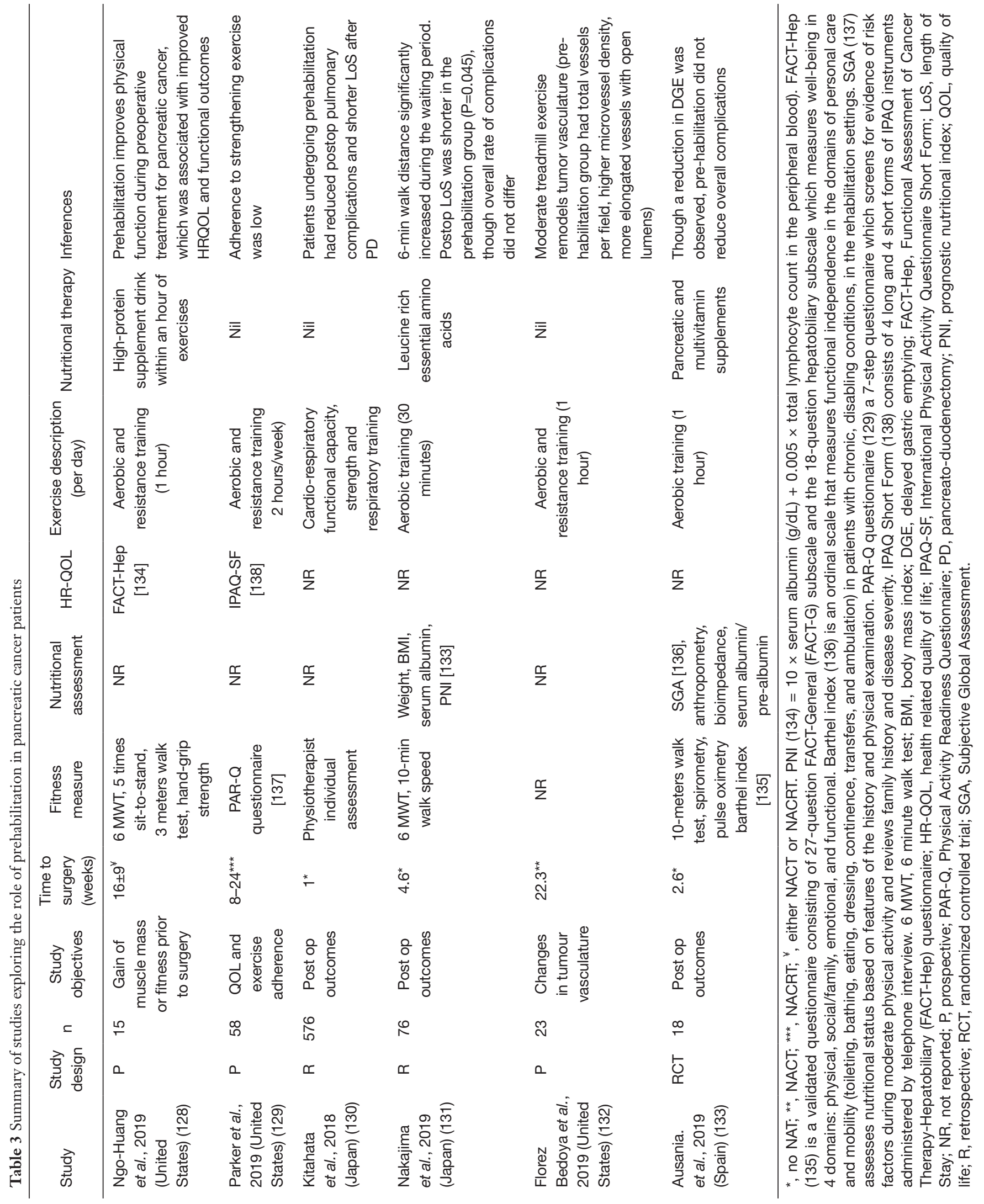


addition to clinical benefits would provide an additional (though not the main) incentive for implementation of ERAS $^{\circledR}$. The universal adoption of ERAS ${ }^{\circledR}$ carried with it the promise of bringing us closer to the "Quadruple Aim" of care, health, cost and meaning in work with overarching aims of improving the individual patient's experience of care, improving the health of populations, reducing the per capita healthcare costs, and improving healthcare worker's experience of providing care (146).

\section{Acknowledgments}

Funding: None.

\section{Footnote}

Provenance and Peer Review: This article was commissioned by the editorial office, Chinese Clinical Oncology, for the series "Unresolved Issues in Pancreatic Cancer". The article has undergone external peer review.

Reporting Checklist: The authors have completed the Narrative Review reporting checklist. Available at http:// dx.doi.org/ 10.21037/cco-21-36

Conflicts of Interest: Both authors have completed the ICMJE uniform disclosure form (available at http://dx.doi. org/10.21037/cco-21-36). The series "Unresolved Issues in Pancreatic Cancer" was commissioned by the editorial office without any funding or sponsorship. Dr. SGB served as the unpaid Guest Editors of the series and serves as an unpaid editorial board member of Chinese Clinical Oncology from December 2020 to November 2022. The authors have no other conflicts of interest to declare.

Ethical Statement: The authors are accountable for all aspects of the work in ensuring that questions related to the accuracy or integrity of any part of the work are appropriately investigated and resolved.

Open Access Statement: This is an Open Access article distributed in accordance with the Creative Commons Attribution-NonCommercial-NoDerivs 4.0 International License (CC BY-NC-ND 4.0), which permits the noncommercial replication and distribution of the article with the strict proviso that no changes or edits are made and the original work is properly cited (including links to both the formal publication through the relevant DOI and the license).
See: https://creativecommons.org/licenses/by-nc-nd/4.0/.

\section{References}

1. Kehlet H. Multimodal approach to control postoperative pathophysiology and rehabilitation. Br J Anaesth 1997;78:606-17.

2. Brindle $M$, Nelson G, Lobo DN, et al. Recommendations from the ERAS ${ }^{\circledast}$ Society for standards for the development of enhanced recovery after surgery guidelines. BJS open 2020;4:157-63.

3. Kehlet H, Mogensen T. Hospital stay of 2 days after open sigmoidectomy with a multimodal rehabilitation programme. Br J Surg 1999;86:227-30.

4. Currie A, Burch J, Jenkins JT, et al. The impact of enhanced recovery protocol compliance on elective colorectal cancer resection: Results from an international registry. Ann Surg 2015;261:1153-9.

5. Ljungqvist O, Young-Fadok T, Demartines N. The History of Enhanced Recovery after Surgery and the ERAS Society. J Laparoendosc Adv Surg Tech A 2017;27:860-2.

6. Ni X, Jia D, Chen Y, et al. Is the Enhanced Recovery After Surgery (ERAS) Program Effective and Safe in Laparoscopic Colorectal Cancer Surgery? A Meta-Analysis of Randomized Controlled Trials. J Gastrointest Surg 2019;23:1502-12.

7. Pisarska M, Malczak P, Major P, et al. Enhanced recovery after surgery protocol in oesophageal cancer surgery: Systematic review and meta-analysis. PLoS One 2017;12:e0174382.

8. Lee Y, Yu J, Doumouras AG, et al. Enhanced recovery after surgery (ERAS) versus standard recovery for elective gastric cancer surgery: A meta-analysis of randomized controlled trials. Surg Oncol 2020;32:75-87.

9. Orejón RU, Torres EM, Martínez IH, et al. Urología Oncológica 2018;71:178-86.

10. Nelson G, Kalogera E, Dowdy SC. Enhanced recovery pathways in gynecologic oncology. Gynecol Oncol 2014;135:586-94.

11. Rogers LJ, Bleetman D, Messenger DE, et al. The impact of enhanced recovery after surgery (ERAS) protocol compliance on morbidity from resection for primary lung cancer. J Thorac Cardiovasc Surg 2018;155:1843-52.

12. Jogerst K, Thomas O, Kosiorek HE, et al. Same-Day Discharge After Mastectomy: Breast Cancer Surgery in the Era of ERAS ${ }^{\circledast}$. Ann Surg Oncol 2020;27:3436-45.

13. Karunakaran M, Barreto SG. ERAS ${ }^{\circledast}$ following 
pancreatoduodenectomy - more than just reducing hospital stay. HPB 2021;23:321.

14. Kleppe KL, Greenberg JA. Enhanced Recovery After Surgery Protocols: Rationale and Components. Surg Clin North Am 2018;98:499-509.

15. Smith TW, Wang X, Singer MA, et al. Enhanced recovery after surgery: A clinical review of implementation across multiple surgical subspecialties. Am J Surg 2020;219:530-4.

16. Gustafsson UO, Hausel J, Thorell A, et al. Adherence to the enhanced recovery after surgery protocol and outcomes after colorectal cancer surgery. Arch Surg 2011;146:571-7.

17. Carli F. Physiologic considerations of Enhanced Recovery After Surgery (ERAS) programs: implications of the stress response. Can J Anesth 2015;62:110-9.

18. Brownlee $M$. The pathobiology of diabetic complications: A unifying mechanism. Diabetes 2005;54:1615-25.

19. Schricker T, Gougeon R, Eberhart L, et al. Type 2 diabetes mellitus and the catabolic response to surgery. Anesthesiology 2005;102:320-6.

20. Ljungqvist O. Modulating postoperative insulin resistance by preoperative carbohydrate loading. Best Pract Res Clin Anaesthesiol 2009;23:401-9.

21. Lewis SJ, Andersen HK, Thomas S. Early enteral nutrition within $24 \mathrm{~h}$ of intestinal surgery versus later commencement of feeding: A systematic review and metaanalysis. J Gastrointest Surg 2009;13:569-75.

22. Kehlet H, Dahl JB. Anaesthesia, surgery, and challenges in postoperative recovery. Lancet 2003;362:1921-8.

23. Alazawi W, Pirmadjid N, Lahiri R, et al. Inflammatory and immune responses to surgery and their clinical impact. Ann Surg 2016;264:73-80.

24. Stavrou G, Kotzampassi K. Gut microbiome, surgical complications and probiotics. Ann Gastroenterol 2017;30:45-53.

25. Greisen J, Juhl CB, Grøfte T, et al. Acute pain induces insulin resistance in humans. Anesthesiology 2001;95:578-84.

26. Schricker T, Wykes L, Carli F. Epidural blockade improves substrate utilization after surgery. Am J Physiol Endocrinol Metab 2000;279:E646-53.

27. Carli F, Emery PW, Freemantle CAJ. Effect of peroperative normothermia on postoperative protein metabolism in elderly patients undergoing hip arthroplasty. Br J Anaesth 1989;63:276-82.

28. Brower RG. Consequences of bed rest. Crit Care Med 2009;37:S422-8.

29. Augestad KM, Delaney CP. Postoperative ileus: Impact of pharmacological treatment, laparoscopic surgery and enhanced recovery pathways. World J Gastroenterol 2010;16:2067-74.

30. Luckey A, Livingston E, Tache Y. Mechanisms and treatment of postoperative ileus. Arch Surg 2003;138:206-14.

31. Mattei P, Rombeau JL. Review of the pathophysiology and management of postoperative ileus. World J Surg 2006;30:1382-91.

32. Chan MKY, Law WL. Use of chewing gum in reducing postoperative ileus after elective colorectal resection: A systematic review. Dis Colon Rectum 2007;50:2149-57.

33. Werawatganon T, Charuluxananan S. Patient controlled intravenous opioid analgesia versus continuous epidural analgesia for pain after intra-abdominal surgery. Cochrane Database Syst Rev 2005;(1):CD004088.

34. Holte K, Kehlet H. Fluid Therapy and Surgical Outcomes in Elective Surgery: A Need for Reassessment in FastTrack Surgery. J Am Coll Surg 2006;202:971-89.

35. Nelson R, Tse B, Edwards S. Systematic review of prophylactic nasogastric decompression after abdominal operations. Br J Surg 2005;92:673-80.

36. Andersen HK, Lewis SJ, Thomas S. Early enteral nutrition within $24 \mathrm{~h}$ of colorectal surgery versus later commencement of feeding for postoperative complications. Cochrane Database Syst Rev 2006;(4):CD004080.

37. Wolff BG, Weese JL, Ludwig KA, et al. Postoperative Ileus-Related Morbidity Profile in Patients Treated with Alvimopan after Bowel Resection. J Am Coll Surg 2007;204:609-16.

38. van Hilst J, Brinkman DJ, de Rooij T, et al. The inflammatory response after laparoscopic and open pancreatoduodenectomy and the association with complications in a multicenter randomized controlled trial. HPB 2019;21:1453-61.

39. Kehlet H. Enhanced postoperative recovery: good from afar, but far from good? Anaesthesia 2020;75:e54-61.

40. Fragiadakis GK, Gaudillière B, Ganio EA, et al. Patientspecific immune states before surgery are strong correlates of surgical recovery. Anesthesiology 2015;123:1241-55.

41. Miller TE, Myles PS. Perioperative Fluid Therapy for Major Surgery. Anesthesiology 2019;130:825-32.

42. Foss NB, Kehlet H. Perioperative haemodynamics and vasoconstriction: time for reconsideration? Br J Anaesth 2019;123:100-3.

43. Jans Ø, Kehlet H. L'intolérance orthostatique postopératoire: malgré un problème périopératoire fréquent, peu de solutions. Can J Anesth 2017;64:10-5. 
44. Bjurström MF, Irwin MR. Perioperative Pharmacological Sleep-Promotion and Pain Control: A Systematic Review. Pain Pract 2019;19:552-69.

45. Subramaniyan S, Terrando N. Neuroinflammation and Perioperative Neurocognitive Disorders. Anesth Analg 2019;128:781-8.

46. Li L, Jin J, Min S, et al. Compliance with the enhanced recovery after surgery protocol and prognosis after colorectal cancer surgery: A prospective cohort study. Oncotarget 2017;8:53531-41.

47. Gustafsson UO, Oppelstrup H, Thorell A, et al. Adherence to the ERAS protocol is Associated with 5-Year Survival After Colorectal Cancer Surgery: A Retrospective Cohort Study. World J Surg 2016;40:1741-7.

48. Siegel RL, Miller KD, Jemal A. Cancer statistics, 2020. CA Cancer J Clin 2020;70:7-30.

49. Søreide K, Nymo LS, Lassen K. Centralization of Pancreatic Surgery in Europe: an Update. J Gastrointest Surg 2019;23:2322-3.

50. Sánchez-Velázquez P, Muller X, Malleo G, et al. Benchmarks in Pancreatic Surgery: A Novel Tool for Unbiased Outcome Comparisons. Ann Surg 2019;270:211-8.

51. Barreto SG, Nair MK, Chaudhary A. Predicting PostPancreatoduodenectomy Complications - Is it Possible? 2016;17:559-60.

52. Lassen K, Coolsen MME, Slim K, et al. Guidelines for perioperative care for pancreaticoduodenectomy: Enhanced Recovery After Surgery (ERAS ${ }^{\circledR}$ ) Society recommendations. Clin Nutr 2012;31:817-30.

53. Melloul E, Lassen K, Roulin D, et al. Guidelines for Perioperative Care for Pancreatoduodenectomy: Enhanced Recovery After Surgery (ERAS) Recommendations 2019. World J Surg 2020;44:2056-84.

54. Myatra S, Divatia J V, Jibhkate B, et al. Preoperative assessment and optimization in periampullary and pancreatic cancer. Indian J Cancer 2011;48:86-93.

55. Reynolds JV, Murchan P, Leonard N, et al. Gut barrier failure in experimental obstructive jaundice. J Surg Res 1996;62:11-6.

56. Karsten TM, Van Gulik TM, Spanjaard L, et al. Bacterial translocation from the biliary tract to blood and lymph in rats with obstructive jaundice. J Surg Res 1998;74:125-30.

57. Clarke DL, Pillay Y, Anderson F, et al. The current standard of care in the periprocedural management of the patient with obstructive jaundice. Ann R Coll Surg Engl 2006;88:610-6.
58. Moher D, Liberati A, Tetzlaff J, et al. Preferred reporting items for systematic reviews and meta-analyses: The PRISMA statement. PLoS Med 2009;6:e1000097.

59. Porter GA, Pisters PWT, Mansyur C, et al. Cost and utilization impact of a clinical pathway for patients undergoing pancreaticoduodenectomy. Ann Surg Oncol 2000;7:484-9.

60. Vanounou T, Pratt W, Fischer JE, et al. Deviation-Based Cost Modeling: A Novel Model to Evaluate the Clinical and Economic Impact of Clinical Pathways. J Am Coll Surg 2007;204:570-9.

61. Kennedy EP, Rosato EL, Sauter PK, et al. Initiation of a Critical Pathway for Pancreaticoduodenectomy at an Academic Institution-the First Step in Multidisciplinary Team Building. J Am Coll Surg 2007;204:917-23.

62. Balzano G, Zerbi A, Braga M, et al. Fast-track recovery programme after pancreaticoduodenectomy reduces delayed gastric emptying. Br J Surg 2008;95:1387-93.

63. Abu Hilal M, Di Fabio F, Badran AA, et al. Implementation of enhanced recovery programme after pancreatoduodenectomy: A single-centre UK pilot study. Pancreatology 2013;13:58-62.

64. Nikfarjam M, Weinberg L, Low N, et al. A fast track recovery program significantly reduces hospital length of stay following uncomplicated pancreaticoduodenectomy. JOP 2013;14:63-70.

65. Braga M, Pecorelli N, Ariotti R, et al. Enhanced recovery after surgery pathway in patients undergoing pancreaticoduodenectomy. World J Surg 2014;38:2960-6.

66. Coolsen MME, Van Dam RM, Chigharoe A, et al. Improving outcome after pancreaticoduodenectomy: Experiences with implementing an Enhanced Recovery After Surgery (ERAS) program. Dig Surg 2014;31:177-84.

67. Kobayashi S, Ooshima R, Koizumi S, et al. Perioperative care with fast-track management in patients undergoing pancreaticoduodenectomy. World J Surg 2014;38:2430-7.

68. Pillai SA, Palaniappan R, Pichaimuthu A, et al. Feasibility of implementing fast-track surgery in pancreaticoduodenectomy with pancreaticogastrostomy for reconstruction - A prospective cohort study with historical control. Int J Surg 2014;12:1005-9.

69. Joliat GR, Labgaa I, Petermann D, et al. Costbenefit analysis of an enhanced recovery protocol for pancreaticoduodenectomy. Br J Surg 2015;102:1676-83.

70. Nussbaum DP, Penne K, Stinnett SS, et al. A standardized care plan is associated with shorter hospital length of stay 
in patients undergoing pancreaticoduodenectomy. J Surg Res 2015;193:237-45.

71. Partelli S, Crippa S, Castagnani R, et al. Evaluation of an enhanced recovery protocol after pancreaticoduodenectomy in elderly patients. HPB 2016;18:153-8.

72. Chaudhary A, Barreto SG, Talole SD, et al. Early discharge after pancreatoduodenectomy: What helps and what prevents. Pancreas 2015;44:273-8.

73. Shao Z, Jin G, Ji W, et al. The role of fast-track surgery in pancreaticoduodenectomy: A retrospective cohort study of 635 consecutive resections. Int J Surg 2015;15:129-33.

74. Sutcliffe RP, Hamoui M, Isaac J, et al. Implementation of an Enhanced Recovery Pathway After Pancreaticoduodenectomy in Patients with Low Drain Fluid Amylase. World J Surg 2015;39:2023-30.

75. Zouros E, Liakakos T, MacHairas A, et al. Improvement of gastric emptying by enhanced recovery after pancreaticoduodenectomy. Hepatobiliary Pancreat Dis Int 2016;15:198-208.

76. Tremblay St-Germain A, Devitt KS, Kagedan DJ, et al. The impact of a clinical pathway on patient postoperative recovery following pancreaticoduodenectomy. HPB 2017;19:799-807.

77. Dai J, Jiang Y, Fu D. Reducing postoperative complications and improving clinical outcome: Enhanced recovery after surgery in pancreaticoduodenectomy - A retrospective cohort study. Int J Surg 2017;39:176-81.

78. Kagedan DJ, Devitt KS, Tremblay St-Germain A, et al. The economics of recovery after pancreatic surgery: detailed cost minimization analysis of an enhanced recovery program. HPB 2017;19:1026-33.

79. Téoule P, Kunz B, Schwarzbach M, et al. Influence of Clinical pathways on treatment and outcome quality for patients undergoing pancreatoduodenectomy? A retrospective cohort study. Asian J Surg 2020;43:799-809.

80. Shah OJ, Bangri SA, Singh M, et al. Impact of centralization of pancreaticoduodenectomy coupled with fast track recovery protocol: a comparative study from India. Hepatobiliary Pancreat Dis Int 2016;15:546-52.

81. Deng X, Cheng X, Huo Z, et al. Modified protocol for enhanced recovery after surgery is beneficial for Chinese cancer patients undergoing pancreaticoduodenectomy. Oncotarget 2017;8:47841-8.

82. Daniel SK, Thornblade LW, Mann GN, et al. Standardization of perioperative care facilitates safe discharge by postoperative day five after pancreaticoduodenectomy. PLoS One 2018;13:e0209608.

83. Takagi K, Yoshida R, Yagi T, et al. Effect of an enhanced recovery after surgery protocol in patients undergoing pancreaticoduodenectomy: A randomized controlled trial. Clin Nutr 2019;38:174-81.

84. Agarwal V, Thomas MJ, Joshi R, et al. Improved Outcomes in 394 Pancreatic Cancer Resections: the Impact of Enhanced Recovery Pathway. J Gastrointest Surg 2018;22:1732-42.

85. Kaman L, Chakarbathi K, Gupta A, et al. Impact of Enhanced Recovery after Surgery protocol on immediate surgical outcome in elderly patients undergoing pancreaticoduodenectomy. Updates Surg 2019;71:653-7.

86. Perinel J, Duclos A, Payet C, et al. Impact of Enhanced Recovery Program after Surgery in Patients Undergoing Pancreatectomy on Postoperative Outcomes: A Controlled before and after Study. Dig Surg 2020;37:47-55.

87. Lavu H, McCall NS, Winter JM, et al. Enhancing Patient Outcomes while Containing Costs after Complex Abdominal Operation: A Randomized Controlled Trial of the Whipple Accelerated Recovery Pathway. J Am Coll Surg 2019;228:415-24.

88. Hwang DW, Kim HJ, Lee JH, et al. Effect of Enhanced Recovery After Surgery program on pancreaticoduodenectomy: a randomized controlled trial. J Hepatobiliary Pancreat Sci 2019;26:360-9.

89. Williamsson C, Karlsson N, Sturesson C, et al. Impact of a fast-track surgery programme for pancreaticoduodenectomy. Br J Surg 2015;102:1133-41.

90. Kleive D, Sahakyan MA, Labori KJ, et al. Nasogastric Tube on Demand is Rarely Necessary After Pancreatoduodenectomy Within an Enhanced Recovery Pathway. World J Surg 2019;43:2616-22.

91. Roulin D, Melloul E, Wellg BE, et al. Feasibility of an Enhanced Recovery Protocol for Elective Pancreatoduodenectomy: A Multicenter International Cohort Study. World J Surg 2020;44:2761-9.

92. Tankel J, Sahnan K, Neumann M, et al. Enhanced Recovery Deviation and Failure After Pancreaticoduodenectomy: Causative Factors and Impact. J Surg Res 2020;245:569-76.

93. Capretti G, Cereda M, Gavazzi F, et al. Enhanced Recovery After Pancreatic Surgery Does One Size Really Fit All? A Clinical Score to Predict the Failure of an Enhanced Recovery Protocol After Pancreaticoduodenectomy. World J Surg 2020;44:3600-6. 94. Hufkens AS, van Cleven S, Abreu de Carvalho 
L, et al. Evaluation of an enhanced recovery program for outcome improvement after pancreaticoduodenectomy: A retrospective cohort study. Int J Surg Open 2021;28:8-16.

95. Kim DH, Yoon YS, Han HS, et al. Effect of enhanced recovery after surgery program on hospital stay and 90day readmission after pancreaticoduodenectomy: A single, tertiary center experience in Korea. Ann Surg Treat Res 2021;100:76-85.

96. Agarwal V, Thomas MJ, Joshi R, et al. Enhanced Recovery After Surgery Protocols: Rationale and Components. World J Surg 2018;14:1-4.

97. <bok $>97$. Roudometof V. Glocalization: A Critical Introduction 1st Edition, 2016.</bok>

98. Nicholson A, Lowe MC, Parker J, et al. Systematic review and meta-analysis of enhanced recovery programmes in surgical patients. Br J Surg 2014;101:172-88.

99. Williamsson C, Karlsson T, Westrin M, et al. Sustainability of an Enhanced Recovery Program for Pancreaticoduodenectomy with Pancreaticogastrostomy. Scand J Surg 2019;108:17-22.

100. Karunakaran M, Barreto SG, Singh MK, et al. Deviations from a clinical pathway post pancreatoduodenectomy predict 90-day unplanned re-admission. Future Oncol 2020;16:1839-49.

101. St-Amour P, St-Amour P, Joliat GR, et al. Impact of ERAS compliance on the delay between surgery and adjuvant chemotherapy in hepatobiliary and pancreatic malignancies. Langenbecks Arch Surg 2020;405:959-66.

102. Altieri MS, Yang J, Yin D, et al. Thirty days are inadequate for assessing readmission following complex hepatopancreatobiliary procedures. Surg Endosc 2019;33:2508-16.

103.Zhang XY, Zhang XZ, Lu FY, et al. Factors associated with failure of enhanced recovery after surgery program in patients undergoing pancreaticoduodenectomy. Hepatobiliary Pancreat Dis Int 2020;19:51-7.

104.Ghaferi AA, Birkmeyer JD, Dimick JB.

Complications, failure to rescue, and mortality with major inpatient surgery in medicare patients. Ann Surg 2009;250:1029-34.

105.Pearsall EA, Meghij Z, Pitzul KB, et al. Qualitative study to understand the barriers and enablers in implementing an enhanced recovery after surgery program. Ann Surg 2015;261:92-6.

106.Ljungqvist O. ERAS - Enhanced Recovery after Surgery: Moving Evidence-Based Perioperative Care to Practice. JPEN J Parenter Enteral Nutr 2014;38:559-66.
107.Pędziwiatr M, Kisialeuski M, Wierdak M, et al. Early implementation of Enhanced Recovery After Surgery $\left(\right.$ ERAS $^{\circledR}$ ) protocol - Compliance improves outcomes: A prospective cohort study. Int J Surg 2015;21:75-81.

108. Roulin D, Najjar P, Demartines N. Enhanced Recovery after Surgery Implementation: From Planning to Success. J Laparoendosc Adv Surg Tech A 2017;27:876-9.

109. Kilo CM. A framework for collaborative improvement: lessons from the Institute for Healthcare Improvement's Breakthrough Series. Qual Manag Health Care 1998;6:1-13.

110. World Health Organization. Regional Office for Europe EO on HS and P, Busse R, Klazinga N, Panteli D, Quentin W. Improving healthcare quality in Europe: Characteristics, effectiveness and implementation of different strategies. Improv Healthc Qual Eur 2019;419. Available online: https://apps.who.int/iris/ bitstream/handle/10665/327356/9789289051750-eng. pdf? sequence $=1$ \&isAllowed $=y$

111. Roulin D, Muradbegovic M, Addor V, et al. Enhanced recovery after elective colorectal surgery - Reasons for non-compliance with the protocol. Dig Surg 2017;34:220-6.

112.Ho CK, Kleeff J, Friess H, et al. Complications of pancreatic surgery. Hpb 2005;7:99-108.

113.Shukla PJ, Barreto SG, Fingerhut A. Do transanastomotic pancreatic ductal stents after pancreatic resections improve outcomes? Pancreas 2010;39:561-6.

114. Callery MP, Pratt WB, Kent TS, et al. A prospectively validated clinical risk score accurately predicts pancreatic fistula after pancreatoduodenectomy. J Am Coll Surg 2013;216:1-14.

115. Tsai S, Choti MA, Assumpcao L, et al. Impact of obesity on perioperative outcomes and survival following pancreaticoduodenectomy for pancreatic cancer: A large single-institution study. J Gastrointest Surg 2010;14:1143-50.

116. Shamali A, Shelat V, Jaber B, et al. Impact of obesity on short and long term results following a pancreaticoduodenectomy. Int J Surg 2017;42:191-6.

117.Su Z, Koga R, Saiura A, et al. Factors influencing infectious complications after pancreatoduodenectomy. J Hepatobiliary Pancreat Sci 2010;17:174-9.

118. House MG, Fong Y, Arnaoutakis DJ, et al. Preoperative predictors for complications after pancreaticoduodenectomy: Impact of BMI and body fat distribution. J Gastrointest Surg 2008;12:270-8.

119.Benns M, Woodall C, Scoggins C, et al. The impact 
of obesity on outcomes following pancreatectomy for malignancy. Ann Surg Oncol 2009;16:2565-9.

120. Williams TK, Rosato EL, Kennedy EP, et al. Impact of Obesity on Perioperative Morbidity and Mortality after Pancreaticoduodenectomy. J Am Coll Surg 2009;208:210-7.

121. Roberts KJ, Hodson J, Mehrzad H, et al. A preoperative predictive score of pancreatic fistula following pancreatoduodenectomy. HPB 2014;16:620-8.

122. Gaujoux S, Cortes A, Couvelard A, et al. Fatty pancreas and increased body mass index are risk factors of pancreatic fistula after pancreaticoduodenectomy. Surgery 2010;148:15-23.

123. Graham JA, Kayser R, Smirniotopoulos J, et al. Probability prediction of a postoperative pancreatic fistula after a pancreaticoduodenectomy allows for more transparency with patients and can facilitate management of expectations. J Surg Oncol 2013;108:137-8.

124. Yasuda K. Bariatric and metabolic surgery in Asia: Where are we, and where are we going? J Diabetes Investig 2018;9:987-90.

125. Pausch T, Hartwig W, Hinz U, et al. Cachexia but not obesity worsens the postoperative outcome after pancreatoduodenectomy in pancreatic cancer. Surgery 2012;152:S81-8.

126.La Torre M, Ziparo V, Nigri G, et al. Malnutrition and pancreatic surgery: Prevalence and outcomes. J Surg Oncol 2013;107:702-8.

127. Barberan-Garcia A, Ubré M, Roca J, et al. Personalised Prehabilitation in High-risk Patients Undergoing Elective Major Abdominal Surgery: A Randomized Blinded Controlled Trial. Ann Surg 2018;267:50-6.

128.Ngo-Huang A, Parker NH, Bruera E, et al. Home-Based Exercise Prehabilitation During Preoperative Treatment for Pancreatic Cancer Is Associated With Improvement in Physical Function and Quality of Life. Integr Cancer Ther 2019;18:1534735419894061.

129. Parker NH, Ngo-Huang A, Lee RE, et al. Physical activity and exercise during preoperative pancreatic cancer treatment. Support Care Cancer 2019;27:2275-84.

130. Kitahata Y, Hirono S, Kawai M, et al. Intensive perioperative rehabilitation improves surgical outcomes after pancreaticoduodenectomy. Langenbecks Arch Surg 2018;403:711-8.

131. Nakajima H, Yokoyama Y, Inoue T, et al. Clinical Benefit of Preoperative Exercise and Nutritional Therapy for Patients Undergoing Hepato-Pancreato-Biliary Surgeries for Malignancy. Ann Surg Oncol 2019;26:264-72.
132. Florez Bedoya CA, Cardoso ACF, Parker N, et al. Exercise during preoperative therapy increases tumor vascularity in pancreatic tumor patients. Sci Rep 2019;9:13966.

133. Ausania F, Senra P, Meléndez R, et al. Prehabilitation in patients undergoing pancreaticoduodenectomy: a randomized controlled trial. Rev Esp Enferm Dig 2019;111:603-8.

134.Li S, Tian G, Chen Z, et al. Prognostic Role of the Prognostic Nutritional Index in Pancreatic Cancer: A Meta-analysis. Nutr Cancer 2019;71:207-13.

135. Cella D, Butt Z, Kindler HL, et al. Validity of the FACT Hepatobiliary (FACT-Hep) questionnaire for assessing disease-related symptoms and health-related quality of life in patients with metastatic pancreatic cancer. Qual Life Res 2013;22:1105-12.

136. Collin C, Wade DT, Davies S, et al. The barthel ADL index: A reliability study. Int Disabil Stud 1988;10:61-3.

137. Castillo-Martínez L, Castro-Eguiluz D, CopcaMendoza ET, et al. Nutritional assessment tools for the identification of malnutrition and nutritional risk associated with cancer treatment. Rev Invest Clin 2018;70:121-5.

138. Lee PH, Macfarlane DJ, Lam TH, et al. Validity of the international physical activity questionnaire short form (IPAQ-SF): A systematic review. Int J Behav Nutr Phys Act 2011;8:115.

139. Bundred JR, Kamarajah SK, Hammond JS, et al. Prehabilitation prior to surgery for pancreatic cancer: A systematic review. Pancreatology 2020;20:1243-50.

140. Barreto SG. Pancreatic cancer: Let us focus on cachexia, not just sarcopenia. Future Oncol 2018;14:2791-4.

141.Kamarajah SK, Bundred J, Weblin J, et al. Critical appraisal on the impact of preoperative rehabilitation and outcomes after major abdominal and cardiothoracic surgery: A systematic review and meta-analysis. Surgery 2020;167:540-9.

142. Patel BY, White L, Gavriilidis P, et al. A systematic review into patient reported outcomes following pancreaticoduodenectomy for malignancy. Eur J Surg Oncol 2021;47:970-8.

143. Denbo JW, Bruno M, Dewhurst W, et al. Risk-stratified clinical pathways decrease the duration of hospitalization and costs of perioperative care after pancreatectomy. Surgery 2018;164:424-31.

144.Kwon MA. Perioperative surgical home: A new scope for future anesthesiology. Korean J Anesthesiol 2018;71:175-81. 
145.Katz MHG, Slack R, Bruno M, et al. Outpatient virtual clinical encounters after complex surgery for cancer: A prospective pilot study of "teleDischarge." J Surg Res 2016;202:196-203.

Cite this article as: Karunakaran M, Barreto SG. Is enhancing recovery after pancreatic cancer surgery even possible?-a narrative review. Chin Clin Oncol 2021;10(5):49. doi: 10.21037/ cco-21-36
146. Sikka R, Morath JM, Leape L. The quadruple aim: Care, health, cost and meaning in work. BMJ Qual Saf 2015;24:608-10. 